\title{
PERAN WORD OF MOUTH DALAM MEMEDIASI HUBUNGAN BRAND AWARENESS DENGAN PURCHASE INTENTION
}

\author{
A.A Istri Wimas Krisyanti ${ }^{1}$ \\ Gede Bayu Rahanatha ${ }^{2}$ \\ ${ }^{1.2}$ Fakultas Ekonomi dan Binis Universitas Udayana (Unud), Bali, Indonesia \\ email: gekkris81@yahoo.com
}

\begin{abstract}
ABSTRAK
Tujuan dari penelitian ini untuk menguji pengaruh brand awareness terhadap purchase intention melalui word of mouth pada calon konsumen Maybelline. Penelitian ini dilakukan di Kota Denpasar dengan responden sebanyak 110 orang. Pengumpulan data dengan penyebaran kuesioner dan diukur menggunakan skala Likert. Teknik analisis yang digunakan adalah path analysis, uji sobel dan uji VAF. Hasil penelitian menemukan bahwa brand awareness berpengaruh positif dan signifikan terhadap purchase intention, brand awareness berpengaruh positif dan signifikan terhadap WOM, WOM berpengaruh positif dan signifikan terhadap purchase intention, serta WOM mampu memediasi pengaruh brand awareness terhadap purchase intention. Implikasi praktis dalam penelitian ini yaitu Manajemen Maybelline dapat meningkatkan periklanannya, melakukan promosi seperti melakukan pemberian kupon kepada konsumen jika merekomendasikan untuk membeli produk Maybelline pada temannya, serta melakukan penguatan image-nya agar dimata konsumen.
\end{abstract}

Kata Kunci: brand awareness, word of mouth, purchase intention

\begin{abstract}
The purpose of this study is to examine the effect of brand awareness on purchase intention through word of mouth on prospective Maybelline consumers. This research was conducted in Denpasar City with 110 respondents. Data collection by distributing questionnaires and measured using a Likert scale. The analysis technique used is path analysis, sobel test and $V A F$ test. The results found that brand awareness has a positive and significant effect on purchase intention, brand awareness has a positive and significant effect on WOM, WOM has a positive and significant effect on purchase intention, and WOM is able to mediate the influence of brand awareness on purchase intention. The practical implication in this research is that Maybelline Management can increase its advertising, carry out promotions such as giving coupons to consumers if they recommend buying Maybelline products to their friends, as well as strengthening their image to the eyes of consumers.

Keywords: brand awareness, word of mouth, purchase intention
\end{abstract}




\section{PENDAHULUAN}

Kosmetik merupakan produk yang unik karena selain memiliki kemampuan untuk memenuhi kebutuhan mendasar wanita akan kecantikan, seringkali menjadi sarana bagi konsumen untuk memperjelas identitas dirinya secara sosial dimata masyarakat, seiring perkembangan jaman kosmetik seolah menjadi kebutuhan primer bagi sebagian kaum wanita. Produk kosmetik pada saat ini makin banyak memproduksi produknya , mulai dari day cream ,foundation, eyeliner, mascara, lipstik, blush on dan produk-produk yang lainnya.

Maybelline adalah produk kosmetik yang didirikan pada tahun 1951 oleh T.L William di New York, amerika serikat. Nama Maybelline merupakan gabungan dari maybel (nama saudara perempuan T.L William yang menjadi inspirasi produknya) dan Vaseline . Perusahaan ini diambil alih oleh L'Oreal Group sejak tahun 1996 hingga saat ini. Maybelline new York adalah brand make up no 1 di dunia, terdepan dalam kualitas dan inovasi dengan identitas New York yang modern dan harga terjangkau. Bersamaan dengan lahirnya slogan "Maybe It's Maybelline" di tahun 1991, brand ini menjadikan kecantikan terjangkau bagi wanita di berbagai penjuru dunia, sehingga masyarakat berkesempatan untuk memaksimalkan potensi mereka. Melalui berbagai komunikasi dengan ikon-ikon cantik dan mempesona dari berbagai etnis termasuk Indonesia. (www.loreal.co.id). Di Indonesia sendiri pemasaran dan penjualan dari setiap produk Maybelline ini sangatlah beragam, terlebih dengan hadirnya toko penjualan produk kosmetik baik yang online maupun yang langsung menjualnya di outlet resmi itu bisa memberikan kemudahan tersendiri bagi setiap calon pembelinya. Salah satu faktor yang mendukung keputusan konsumen dalam membeli sebuah produk adalah merek.

Purchase Intention adalah sesuatu yang timbul setelah menerima rangsangan dari produk yang dilihatnya, lalu muncul kecenderungan calon konsumen untuk mencoba produk dan muncul keinginan untuk membeli dan memilikinya. Setiap orang yang ingin memenuhi kebutuhannya memiliki beberapa bahan pertimbangan sebelum memutuskan untuk membeli barang pemuas kebutuhannya tersebut. Salah satu pertimbangan dalam memilih barang adalah merek (Kusuma, 2014). Saat ini berbagai macam promosi telah dilakukan oleh brand-brand ternama, mulai dari promosi iklan sampai meng-endorse produk mreka ke selebgram dan beauty bloger untuk merangsang niat konsumen untuk membeli produk mereka. Niat beli (purchase intention) adalah suatu hal yang merefleksikan rencana pembelian sejumlah produk dengan merek tertentu (Aditya dan Wardana, 2017). Niat beli adalah tahap dimana konsumen dalam membentuk pilihan mereka diantara beberapa merek yang tergabung dalam perangkat pilihan, kemudian pada akhirnya melakukan suatu pembelian pada suatu alternatif yang paling disukainya atau proses yang dilalui konsumen untuk membeli suatu barang atau jasa yang didasari oleh bermacam pertimbangan (Annafik dkk., 2012 dan Rahardjo, 2012). Trisnawati dkk. (2012) menyatakan niat konsumen untuk melakukan pembelian dipengaruhi oleh banyak faktor, selain dari pengalaman dirinya sendiri tetapi juga dapat dipengaruhi oleh pendapat atau rekomendasi dari 
konsumen lain yang pernah membeli atau mengkonsumsi produk tersebut yang dikenal dengan sebutan word of mouth (WOM). Niat beli adalah tahap kecenderungan responden untuk bertindak sebelum benar-benar melakukan pembelian (Martinez dan Kim, 2012). Niat beli konsumen adalah tahap dimana konsumen membentuk pilihan mereka diantara beberapa merek yang tergabung dalam perangkat pilihan, kemudian pada akhirnya melakukan suatu pembelian pada suatu altenatif yang paling disukainya atau proses yang dilalui konsumen untuk membeli suatu barang atau jasa yang didasari oleh bermacam pertimbangan (Ruhamak dan Rahayu, 2016), Niat pembelian menunjukkan keinginan seorang konsumen untuk melakukan pembelian pada perusahaan (Li, 2010).

Munculnya nama merek tetentu di benak konsumen ketika hendak membeli suatu produk, mengindikasikan produk tersebut memiliki kesadaran merek yang tinggi (Chi et al., 2009). Hsu dan Hsu (2014) menyatakan bahwa konsumen cenderung memilih merek yang familiar, merek yang familiar mengindikasikan kesadaran konsumen terhadap merek tersebut tinggi. Mengingat kembali suatu merek sebagai bagian dari suatu kategori produk tertentu. Peran kesadaran merek dalam ekuitas merek tergantung pada tingkat akan pencapaian kesadaran dibenak konsumen (Sudjianto, 2014). Konsumen yang sudah mengetahui suatu merek, selanjutnya akan membentuk sikap terhadap merek tersebut. Seorang konsumen akan cenderung lebih percaya terhadap rekomendasi melalui jalur Word of Mouth daripada metode formal dikarenakan pemberi rekomendasi diyakini bicara jujur, tulus dan tidak ditunggangi oleh motif tersembunyi. Promosi dapat dilakukan dengan suatu komunikasi yaitu word of mouth.

Word of Mouth adalah komunikasi berupa pembicaraan maupun testimonial yang dilakukan orang yang membicarakan mengenai suatu produk atau jasa (Basalamah, 2010). Menurut Widjaja (2016) Word of mouth adalah tindakan konsumen memberikan informasi kepada konsumen lain (antar pribadi) nonkomersial baik merek, produk maupun jasa. Word of mouth telah dinyatakan oleh Murtiasih et al. (2013) bahwa word of mouth mempengaruhi brand awareness secara signifikan dalam arah yang positif. Bentuk Word of Mouth yang baru ini telah menjadi faktor penting dalam pembentukan perilaku konsumen. Rekomendasi WOM positif akan meningkat karena tingkat niat beli untuk pelanggan meningkat (Chiu et al., 2016). Adanya rekomendasi ataupun review yang diberikan konsumen lain misal dalam sebuah sharing review platform ataupun komunitas akan mampu mempengaruhi Purchase Intention konsumen. Menurut Zamil (2011). Hubungan Word Of Mouth terhadap Keputusan Pembelian dapat dijelaskan sebagai berikut :hasil analisis yang dilakukan menujukkan adanya hubungan yang positif,kuat,dan secara signifikan Word of Mouth, dalam pemasaran terhadap suatu produk terhadap keputusan pembelian. Word of mouth (WOM) ialah perilaku mempengaruhi orang lain dalam bentuk penyampaian informasi mengenai produk baik barang maupun jasa kepada orang lain (Sulistyowati, 2008).

Saat ini Maybelline mengeluarkan lipstik matte yang dimana lipstik ini memiliki kualitas yang sangat baik dan harga nya tidak terlalu mahal. Banyak selebgram-selebgram yang me-rivew produk Maybelline lipstik matte sehingga masyarakat bisa mudah tertarik untuk membeli produk tersebut. 
Penelitian ini memilih lokasi penelitian di Denpasar, karena banyak kaum wanita mulai dari mahasiswa, wanita pekerja yang wajib menggunakan makeup maupun makeupartist yang berdomisili di Denpasar. Seorang makeup artist pasti akan memilih produk terbaik untuk merias wajah konsumen nya agar terlihat sempurna, maka dari itu mereka harus sangat selektif untuk memilih produk yang digunakan. Banyaknya makeupartist menyediakan produk yang berbeda, ada yang menggunakan produk yang murah agar mereka bisa memberikan harga yang terjangkau untuk konsumen nya, namun banyak juga makeup artist yang memilih produk-produk makeup terkenal yang harganya tidak murah agar pelanggan mereka terhindar dari produk yang bisa merusak wajah.

Brand Awareness menggambarkan kesanggupan seorang calon pembeli untuk mengenali, mengingat kembali suatu merek sebagai bagian dari suatu kategori produk tertentu. Merek yang sering dibeli oleh keluarga biasanya akan membuat seluruh anggota keluarga memiliki kesadaran yang tinggi akan keberadaan merek (Erna Ferinnadewi, 2008:174). Setiap orang yang ingin memenuhi kebutuhannya memiliki beberapa bahan pertimbangan sebelum memutuskan untuk membeli barang pemuas kebutuhannya tersebut. Salah satu pertimbangan dalam memilih barang adalah merek. Konsumen cenderung akan memutuskan untuk membeli sebuah produk yang mereknya sudah dikenal olehnya daripada sebuah produk yang mereknya kurang dikenal atau bahkan tidak dikenal sama sekali. Dalam proses pembelian, Brand Awareness mempengaruhi keinginan konsumen untuk membeli suatu produk seperti dijelaskan Durianto (2001:56) dimana Brand Awareness memberikan nilai melalui empat cara yaitu jangkar tempat tautan berbagai asosiasi, familier/rasa suka, substansi/komitmen, mempertimbangkan merek. Nilai keempat dalam Brand Awareness menjelaskan langkah pertama dalam suatu proses pembelian adalah menyelaksi merek yang dikenal dalam suatu kelompok untuk di putuskan merek mana yang akan dibeli. Merek dengan top of mind yang tinggi memiliki nilai pertimbangan yang tinggi. Jika suatu merek tidak tersimpan dalam ingatan, merek tersebut tidak akan dipertimbangkan dalam benak konsumen. Aaker (2013) mengemukakan bahwa strategi bisnis dapat terbentuk melalui asset merek. Merek memungkinkan bagi perusahaan untuk berkompetisi dalam pasar produk dan jasa serta menunjukkan proposisi nilai dari strategi bisnis. Jadi, secara strategis sangat penting untuk mengembangkan asset merek. Brand Awareness juga sangat berpengaruh pada penjualan produk Maybelline lipstik matte ini, hampir seluruh masyarakat Indonesia yang addict pada makeup sudah mengetahui bahwa Maybelline bukanlah produk yang abal-abal. Brand Awareness yaitu kemampuan konsumen untuk mengenali atau mengingat bahwa sebuah merek merupakan anggota dari kategori tertentu. (Fandy Tjiptono, 2011 : 97). Merek memberikan arti penting bagi kompetisi di dunia usaha. Banyak sekali merek-merek yang tadinya populer namun lambat laun semakin menurun bahkan hilang dari pasaran. Semakin beragamnya merek kosmetik membuat problem yang dihadapi perusahaan semakin kompleks. Berdasarkan hasil dari survey Top Brand Index pada tahun 2018 untuk kategori kosmetik lipstik adalah sebagai berikut: 
Tabel 1.

Top Brand Index Pada Tahun 2018 Untuk Kategori Kosmetik Lipstik

\begin{tabular}{ccc}
\hline MEREK & TBI & TOP \\
\hline Wardah & $29.4 \%$ & TOP \\
Pixy & $14.9 \%$ & TOP \\
Red-A & $10.1 \%$ & TOP \\
Maybelline & $8.9 \%$ & \\
Puteri & $3.5 \%$ & \\
\hline
\end{tabular}

Sumber: Top Brand Indeks, 2018

Pada Tabel 1. produk Maybelline berada di urutan ke 4 dalam Top Brand Indeks 2018 diantara 5 produk kosmetik ternama di Indonesia, dimana di urutan pertama ditempati oleh wardah dengan penjualan mencapai $29.4 \%$ dan di urutan kedua di tempati oleh Pixy dengan penjualan mencapai $14.9 \%$, di urutan ketiga di tempati oleh Red-A dengan penjualan $10.1 \%$, selanjutnya Maybelline menempati urutan keempat dengan penjualan $8.9 \%$ dan di urutan terakhir di tempati oleh Puteri dengan penjualan $3.5 \%$.

Brand Maybelline sudah terkenal sejak lama, namun saat ini mulai lagi gencar mengeluarkan produk-produk barunya yang sangat menarik dan menjadi salah satu produk yang paling sering dicari wanita yang menyukai kosmetik. Oleh karena itu, tulisan ini berupaya memberikan penjelasan mengenai hubungan Brand awareness, Word of Mouth, dan Purchase Intention terhadap Produk Kosmetik Maybelline.

Untuk melihat seberapa besar Purchase Intention konsumen pada produk Maybelline maka dilakukan pra survey dengan menyebarkan kuisioner sementara terdiri dari indikator brand awareness, word of mouth, dan purchase intention yang disebarkan kepada 30 orang responden. Berdasarkan penyebaran kuisioner tersebut, diperoleh data sebagai berikut :

Tabel 2.

\begin{tabular}{lllll}
\multicolumn{2}{c}{$\begin{array}{c}\text { Hasil Kuisioner Pra-Survey Mengenai Brand awareness, Word of mouth, } \\
\text { Purchase intention pada pembelian produk Maybelline di Denpasar. }\end{array}$} \\
\hline No & Pertanyaan & YA & TIDAK \\
\hline 1 & $\begin{array}{l}\text { Saya mengetahui produk Maybelline } \\
\text { Saya sadar bahwa produk Maybelline itu } \\
\text { bagus }\end{array}$ & 30 & 0 & 8 \\
3 & $\begin{array}{l}\text { Saya mengetahui produk ini karena } \\
\text { rekomendasi dari teman }\end{array}$ & 14 & 16 & 11 \\
\hline & $\begin{array}{l}\text { Saya berniat untuk membeli } \\
\text { produk Maybelline }\end{array}$ & 19 & 16
\end{tabular}

Sumber: Data diolah, 2018

Dari Tabel 2. diatas didapatkan hasil 30 orang yang mengetahui produk Maybelline, rata-rata hampir seluruh kaum wanita mengetahui produk Maybelline karena terkenal dengan harga yang masih terjangkau dan memiliki kualitas yang sangat baik. 22 orang sadar bahwa produk Maybelline itu bagus, banyak selebriti yang sudah me-rivew produk Maybelline ini di youtube dimana salah satu dari produk Maybelline yaitu "Maybelline lipstik mate" sangatlah tahan lama namun dari hasil survey 8 orang lainnya mengatakan produk Maybelline itu tidak bagus 
karena ada juga orang yang tidak cocok menggunakan produk Maybelline, salah satu dari 8 orang tersebut mengatakan usai menggunakan salah satu produk dari Maybelline yaitu "Maybelline lipstik mate" mengatakan bibirya kering lantaran Maybelline lipstik mate tersebut. Selanjutnya ada 14 orang yang merekomendasikan produk Maybelline kepada temannya, mereka secara tidak langsung seringkali merekomendasikan produk Maybelline ke teman dekat mereka karena Maybelline sering mengeluarkan produk baru yang dimana produk tersebut pasti akan ramai menjadi perbincangan kaum wanita penggemar kosmetik, namun 16 orang lainnya tidak berniat merekomendasikan ke teman mereka, karena mereka menganggap sebagian besar wanita yang gemar memakai kosmetik pasti sudah mengetahui bawha produk Maybelline itu bagus dan harga nya terjangkau, dan ada 19 orang yang berniat untuk membeli produk Maybelline karena sudah melihat riview maupun mendapat rekomendasi dari teman sekitarnya mengenai produk-produk Maybelline, namun 11 orang yang lain tidak ada keinginan untuk membeli karena mereka sudah menggunakan produk kosmetik yang lain dan enggan untuk berlalih ke Maybelline.

Setiap orang yang ingin memenuhi kebutuhannya memiliki beberapa bahan pertimbangan sebelum memutuskan untuk membeli barang pemuas kebutuhannya tersebut. Salah satu pertimbangan dalam memilih barang adalah merek. Berdasarkan penelitian yang di lakukan oleh Petahiang dkk. (2015) dapat dijelaskan bahwa efek pada Brand Awareness konsumen di toko online OLX di FEB Unsrat Manado dengan koefisien yang signifikan. Hasil penelitian ini bersama-sama dan mendukung penelitian sebelumnya dari penelitian Chi et al., (2009) di mana penelitian ini menemukan bahwa variabel brand awareness mempengaruhi Purchase Intention. Konsumen cenderung akan memutuskan untuk membeli sebuah produk yang mereknya sudah dikenal olehnya daripada sebuah produk yang mereknya kurang dikenal atau bahkan tidak dikenal sama sekali Durianto et al. dalam Andriyanto dan Haryanto (2010). Dari penjelasan di atas maka dirumuskan hipotesis sebagai berikut:

$\mathrm{H}_{1}$ : Brand awareness berpengaruh positif terhadap Purchase Intention konsumen

Kemampuan interaktif dan komunikatif mereka yang luar biasa, Jaringan Sosial Online (OSN) memungkinkan tujuan dan perusahaan untuk meningkatkan Brand Awareness mereka. Banyak tujuan wisata dan perhotelanmerek mengeksplorasi penggunaan OSN untuk membentuk Brand Awareness dan menghasilkan WOM positif. Barreda et al. (2015), menyatakan bahwa Brand Awareness dapat meningkatkan traffic WOM. Hal ini juga di dukung dari penelitian yang sudah dilakukan oleh (Katja et al., 2013), dan Liao (2012). Hasil dari penelitian ini adalah Brand Awareness berpengaruh secara signifikan terhadap Word of Mouth. Dari penjelasan tersebut maka dirumuskan hipotesis sebagai berikut:

$\mathrm{H}_{2}$ : Brand Awareness berpengaruh positif terhadap Word Of Mouth

Word of mouth diketahui dapat memengaruhi niat beli seseorang (Nurvidiana dkk., 2015). Solomon dalam Andriyanto \& Haryanto (2010) mengatakan bahwa word of mouth lebih kuat dari pada iklan-iklan mewah yang 
dibuat oleh perusahaan. Seorang konsumen akan cenderung lebih percaya terhadap rekomendasi melalui jalur word of mouth daripada metode formal dikarenakan pemberi rekomendasi diyakini bicara jujur, tulus dan tidak ditunggangi oleh motif tersembunyi Andriyanto dan Haryanto (2010). Dari penjelasan tersebut maka dirumuskan hipotesis sebagai berikut:

$\mathrm{H}_{3}$ : Word of mouth berpengaruh positif terhadap Purchase Intention konsumen

Word of Mouth secara luas dianggap sebagai pengaruh yang kuat di pasar konsumen, terutama pada pencarian informasi konsumen dan pengambilan keputusan selanjutnya. Brown dan Reingen (1987) mengemukakan bahwa Word of Mouth atau komunikasi dari mulut ke mulut merupakan proses komunikasi yang berupa pemberian rekomendasi baik secara individu maupun kelompok terhadap suatu produk atau jasa yang bertujuan untuk memberikan informasi secara personal. Word of Mouth dapat menjadi metode pemasaran yang efektif, karena disampaikan dari, untuk dan oleh konsumen yang satu kepada konsumen yang lainnya. Promosi menggunakan WOM juga tidak membutuhkan biaya yang besar, pelanggan yang puas akan menyebarkan informasi mengenai produk atau jasa yang dia beli. Hasil mendukung Lin et al. (2013), menemukan bahwa word of mouth mempengaruhi purchase intention.

Chi et al. (2009) menyatakan Brand Awareness dapat mempengaruhi Purchase Intention secara signifikan baik melalui kualitas yang dirasa maupun loyalitas merek. Penelitian Yaseen et al. (2011) menunjukkan adanya hubungan signifikansi antara Brand Awareness terhadap niat konsumen untuk membeli suatu produk. Grewal, Monroe \& Krishnan (1998) dalam Anwar dan Gulzar (2011) berpendapat "high brand awareness can influence the retailer or reseller purchase decision" yang artinya Brand Awareness yang tinggi akan mempengaruhi pengecer atau penjual ulang memutuskan untuk membeli.

$\mathrm{H}_{4}$ : Word Of Mouth memediasi pengaruh Brand Awareness terhadap Purchase Intention.

\section{METODE PENELITIAN}

Penelitian ini dilakukan di Denpasar, lokasi ini dipilih karena Denpasar wilayah pemasaran yang sangat menarik bagi produsen makeup. Dalam penelitian ini yang menjadi populasi adalah seluruh masyarakat yang berdomisili di Denpasar yang belum menggunakan produk Maybelline. Di samping itu populasi subjek penelitian sangat homogen. Jadi perhitungan jumlah sampel responden yang akan diuji adalah sebagai berikut.

Jumlah Responden = Jumlah Indikator x 10

$$
\begin{aligned}
& =11 \text { indikator } \mathrm{x} 10 \\
& =110 \text { responden }
\end{aligned}
$$

Sehingga jumlah ukuran sampel yang digunakan pada studi ini adalah sejumlah 110 responden. Analisis jalur digunakan untuk menentukan pola hubungan antara tiga atau lebih dan tidak dapat digunakan untuk mengkonfirmasi atau menolak hipotesis.

Persamaan sub-struktural 1 


$$
\mathrm{M}=\beta_{2} \mathrm{X}+\mathrm{e}_{1}
$$

Persamaan sub-struktural 2

$$
\mathrm{Y}_{2}=\beta_{1} \mathrm{X}+\beta_{3} \mathrm{Y}_{1}+\mathrm{e}_{2}
$$

Keterangan:

$$
\begin{aligned}
& \mathrm{X} \quad=\text { Brand Awareness } \\
& \mathrm{M} \quad=\text { Word of Mouth } \\
& \mathrm{Y}=\text { Purchase Intention } \\
& \beta_{1}, \beta_{2}, \beta_{3} \quad=\text { koefisien regresi variabel } \\
& \mathrm{e}=\text { error }
\end{aligned}
$$

\section{HASIL DAN PEMBAHASAN}

Mabel Williams pada tahun 1915, seorang perempuan muda dari Chicago, sedang mencari cara untuk meningkatkan matanya. Dengan mata untuk kecerdikan, ia diaduk bersama debu batu bara dan Vaseline dan diterapkan campuran untuk bulu matanya dan alisnya. Terinspirasi oleh potensi penemuan tenunan nya, kakaknya Thomas Lyle Williams menciptakan Maybell Laboratorium dan mulai menjual maskara melalui pos. Perempuan di seluruh AS segera berteriak-teriak untuk Maybelline, dan pada tahun 1930 perusahaan menanggapi dengan menjual ke toko varietas lokal. Sejak saat itu, berbagai produk legendaris tumbuh.

Tahun 1971, setelah setengah abad inovasi yang berkelanjutan, Maybelline membuat gelombang di dunia kosmetik dengan memperkenalkan revolusioner, berbasis air besar Lash Mascara dalam warna pink dan kemasan hijau. Sejak saat itu telah menjadi salah satu produk kecantikan yang paling banyak terjual di dunia dan favorit mutlak di kalangan selebriti dan seniman makeup. Hari ini, Maybelline New York memimpin kategori maskara dengan ikon garis Volume 'Express-nya: The Colossal adalah instan di seluruh dunia memukul, dan tak lama setelah peluncuran pada tahun 2010, Maybelline menjadi produk mascara no satu di dunia.

Sebuah inovasi terobosan wajah datang pada tahun 2004 dengan peluncuran Cream, barisan riasan, blush, bronzer, dan concealer. Pada tahun 2009, Maybelline New York mengubah kategori lagi dengan peluncuran $B B$ cream pertama di Asia. Sejak itu, jutaan wanita di seluruh dunia telah jatuh cinta dengan formula unik Cream segar BB 8-in-1 Perfector kulit. Dalam kategori bibir, Maybelline New York memperkenalkan koleksi warna yang paling komprehensif di massa dengan warna sensasional tahun 2009 Array besar warna dibagi menjadi empat keluarga warna yang memungkinkan perempuan untuk dengan mudah mengidentifikasi warna yang diinginkan. Sebuah hit besar dengan warna yang tajam yang lembut, rentang terus memberikan nuansa berani selaras dengan tren saat ini. Keberhasilan terbaru dari Maybelline New York adalah pengenalan warna tampilkan cat kuku pada 2012 kisaran tekstur edgy, warna, dan efek terinspirasi oleh landasan pacu New York membuat fashion must-have kuku terlihat diakses oleh semua. 
Tahun 2009 menandai tonggak fashion untuk Maybelline New York. Setelah Amsterdam, Berlin dan Moskow, merek mengamankan gelar juara didambakan resmi makeup sponsor dari Mercedes-Benz Fashion Week di kota nya New York City. Sejak itu, Maybelline telah menampilkan kreativitas dan keahlian di landasan pacu, berkolaborasi dengan perancang busana untuk mengembangkan tren kecantikan musim depan. Hari ini, Maybelline New York bangga menjadi susunan sponsor resmi tiga belas mode minggu di seluruh dunia.

Dengan kemewahan dan energi New York City, inovasi makeup utama, dan fashion terbaru terlihat dari catwalk ke trotoar, Maybelline New York memberdayakan perempuan di seluruh dunia untuk mengekspresikan pribadi "itu" faktor mereka.

Maybelline New York adalah merek kosmetik terkemuka di dunia, tersedia di lebih dari 100 negara. Dengan menggabungkan formulasi berteknologi maju dengan keahlian on-tren dan New York City tepi, misi Maybelline New York adalah untuk menawarkan inovatif, dapat diakses, dan mudah kosmetik bagi setiap wanita.

Penelitian ini menggunakan sampel responden sebanyak 110 orang.

Tabel 3.

Karakteristik Responden konsumen Maybelline kota Denpasar

\begin{tabular}{|c|c|c|c|c|}
\hline No. & Karakteristik & Klasifikasi & $\begin{array}{c}\text { Jumlah } \\
\text { Responden } \\
\text { (orang) }\end{array}$ & $\begin{array}{c}\text { Persentase } \\
\text { Responden } \\
(\%)\end{array}$ \\
\hline \multirow[t]{3}{*}{1} & Jenis kelamin & Laki-laki & 3 & 2,7 \\
\hline & & Perempuan & 107 & 97,3 \\
\hline & & & 110 & 100 \\
\hline \multirow[t]{5}{*}{2} & Usia & $17-20$ & 41 & 37,2 \\
\hline & & $21-24$ & 32 & 29,1 \\
\hline & & $25-28$ & 28 & 25,5 \\
\hline & & $29-31$ & 9 & 8,2 \\
\hline & & & 110 & 100 \\
\hline
\end{tabular}

Sumber : Data diolah, 2018

Pada Tabel 3. menunjukkan bahwa berdasarkan karakteristik jenis kelamin responden, dimana semua responden berjenis kelamin perempuan memiliki yaitu 107 orang dengan persentase sebesar 97,3\% dan laki-laki sebanyak 3 orang yaitu sebesar 2,7\%. Hal ini menyatakan bahwa konsumen Maybelline di Kota Denpasar didominasi oleh perempuan.

Berdasarkan karakteristik usia responden, dapat dilihat bahwa responden dengan usia 17-20 tahun memiliki jumlah responden terbanyak yaitu sebanyak 41 orang dengan persentase $37,2 \%$, berusia 21-24 tahun sebanyak 32 orang dengan persentase $29,1 \%$, berusia $25-28$ tahun sebanyak 28 orang dengan persentase $25,5 \%$. Sedangkan sisanya sebesar $8,2 \%$ berusia $29-31$ tahun dengan jumlah responden sebanyak 9 orang.

Brand Awareness yang dimiliki Maybelline dalam benak konsumen adalah sangat baik. Hal ini dapat dilihat dari keseluruhan rata-rata nilai dari Brand Awareness yaitu 4,23. Nilai rata-rata tertinggi terletak pada pernyataan "Saat ini 
anda sudah mengetahui Produk Maybelline" dengan nilai rata-rata 4,39. Hal ini menunjukkan bahwa konsumen sudah mengetahui produk Maybelline sebelumnya.

Nilai rata-rata terendah terdapat pada pernyataan "Maybelline adalah merek produk kosmetik yang paling anda ingat" dengan nilai rata-rata 3,98. Hal ini dapat mengindikasikan bahwa beberapa konsumen tidak begitu mengingat merek Maybelline dibanding dengan merek pesaing lainnya yang dimana mungkin saja diakibatkan dari kurang adanya penyebarluasan informasi mengenai merek Maybelline itu sendiri.

Secara keseluruhan rata-rata jawaban responden terhadap variabel Word of Mouth memiliki nilai 3,86 yang menyatakan bahwa Word of Mouth terhadap Maybelline baik. Hasil penyebaran kuesioner menunjukkan bahwa pernyataan "Teman-Teman anda mengatakan hal-hal positif tentang Produk Maybelline" memiliki nilai rata-rata paling tinggi yaitu 4,04. Hal ini menyatakan bahwa temanteman dari responden memberikan opini yang positif tentang produk Maybelline, opini positif ini bisa terjadi karena konsumen merasa puas dengan produk Maybelline.

Nilai rata-rata terendah terdapat pada pernyataan "Teman-Teman merekomendasikan anda untuk membeli Produk Maybelline" dengan nilai ratarata sebesar 3,76. Hal ini menunjukkan bahwa teman-teman responden meskipun menyebarkan hal-hal positif tentang produk Maybelline namun tidak semua merekomendasikan untuk membeli produk Maybelline hal ini mungkin terjadi jika mereka menemukan produk yang lebih baik dari produk pesaing dibanding Maybelline atau karena faktor lainnya.

Secara keseluruhan rata-rata jawaban responden terhadap variabel kepercayaan konsumen memiliki nilai sebasar 3,68. Hasil penyebaran kuesioner menunjukkan bahwa Purchase Intention ulang konsumen terhadap Maybelline tinggi. Nilai rata-rata tertinggi terdapat pada pernyataan "Anda selama ini mencari informasi tentang produk Maybelline" dengan nilai rata-rata 3,82. Hal ini menunjukkan bahwa Purchase Intention konsumen terhadap Maybelline tinggi. Nilai rata-rata terendah terdapat pada pernyataan "Anda lebih memilih produk Maybelline dibandingkan produk lainnya", dengan nilai rata-rata 3,55. Hal ini menunjukkan bahwa konsumen belum tentu menjatuhkan pilihan kepada Maybelline pada saat akan melakukan pembelian produk sejenis dibanding produk lainnya.

Suatu instrumen dikatakan valid apabila memiliki koefisien korelasi antara butir dengan skor total dalam instrumen tersebut lebih besar dari 0,30. Tabel 4.2 berikut menyajikan hasil uji validitas instrumen penelitian.

Hasil uji validitas pada Tabel 4. menunjukkan bahwa seluruh instrumen penelitian yang digunakan untuk mengukur variabel Brand Awareness, Word of Mouth, dan Purchase Intention memiliki nilai koefisien korelasi dengan skor total seluruh item pertanyaan lebih dari 0,30 . Hal ini menunjukkan bahwa butir-butir pernyataan dalam instrumen penelitian tersebut valid dan layak digunakan sebagai isntrumen penelitian. 
Tabel 4.

Rekapitulasi Hasil Uji Validitas Instrumen Penelitian

\begin{tabular}{cccc}
\hline Variabel & Indikator & $\begin{array}{c}\text { Koefisien } \\
\text { Korelasi }\end{array}$ & Keterangan \\
\hline Brand Awareness & X1 & 0,955 & Valid \\
(X) & X2 & 0,929 & Valid \\
& X3 & 0,874 & Valid \\
WOM & M.1 & 0,904 & Valid \\
(M) & M.2 & 0,980 & Valid \\
& M.3 & 0,980 & Valid \\
Purchase Intention & Y.1 & 0,863 & Valid \\
(Y) & Y.2 & 0,901 & Valid \\
\hline
\end{tabular}

Sumber : Data diolah, 2018

Uji reliabilitas terhadap instrumen penelitian ini menggunakan nilai Cronbach's Alpha. Nilai Cronbach's Alpha dinyatakan reliabel jika nilainya lebih besar atau sama dengan 0,60. Rekapitulasi uji reliabilitas instrumen penelitian dapat dilihat pada Tabel 5 berikut.

Tabel 5.

Rekapitulasi Hasil Uji Reliabilitas Instrumen Penelitian

\begin{tabular}{cccc}
\hline No & Variabel & Cronbach's Alpha & Keterangan \\
\hline 1 & Brand Awareness & 0,868 & Reliabel \\
2 & WOM & 0,878 & Reliabel \\
3 & Purchase Intention & 0,860 & Reliabel \\
\hline
\end{tabular}

Sumber : Data diolah, 2018

Hasil uji reliabilitas yang disajikan dalam Tabel 3. menunjukkan bahwa seluruh instrumen penelitian memiliki koefisien Cronbach's Alpha lebih dari 0,60 . Jadi dapat dinyatakan bahwa seluruh variabel telah memenuhi syarat reliabilitas atau kehandalan sehingga dapat digunakan untuk melakukan penelitian.

Perhitungan koefisien path dilakukan dengan analisis regresi melalui software SPSS 24.0 for Windows, diperoleh hasil yang ditunjukkan pada Tabel 6 berikut ini.

Tabel 6.

Hasil Analisis Jalur I

\begin{tabular}{|c|c|c|c|c|c|}
\hline \multirow[t]{2}{*}{ Variabel } & \multicolumn{2}{|c|}{ Unstandardized Coefficients } & \multirow{2}{*}{$\begin{array}{c}\begin{array}{c}\text { Standardized } \\
\text { Coefficients }\end{array} \\
\text { Beta }\end{array}$} & \multirow[t]{2}{*}{ t hitung } & \multirow[t]{2}{*}{ Sig. uji t } \\
\hline & B & Std. Error & & & \\
\hline (Constant) & 1,365 & 1,011 & & 1,349 & 0,180 \\
\hline Brand & 0,805 & 0,079 & 0,700 & 10,198 & 0,000 \\
\hline Awareness (X) & & & & & \\
\hline $\begin{array}{l}\text { R Square } \\
\text { F Statistik } \\
\text { Signifikansi Uji } \\
\text { F }\end{array}$ & $\begin{array}{l}0,491 \\
103,997 \\
0,000\end{array}$ & & & & \\
\hline
\end{tabular}


Berdasarkan hasil analisis jalur sub struktur 1 seperti yang disajikan pada Tabel 6, maka dapat dibuat persamaan struktural sebagai berikut :

$$
\begin{aligned}
& \mathrm{M}=\beta 2 \mathrm{X}+\mathrm{e} 1 \\
& \mathrm{M}=0,700 \mathrm{X}+\mathrm{e} 1
\end{aligned}
$$

Besarnya pengaruh variabel bebas terhadap variabel terikat yang ditunjukkan oleh nilai determinasi total (R square) sebesar 0,491 mempunyai arti bahwa sebesar 49,1 \% variasi Word of Mouth dipengaruhi oleh variasi Brand Awareness, sedangkan sisanya sebesar $50,9 \%$ dijelaskan oleh faktor lain yang tidak dimasukkan kedalam model.

Tabel 7.

\begin{tabular}{|c|c|c|c|c|c|}
\hline Variabel & Unstandardized C & efficients & $\begin{array}{l}\text { Standardized } \\
\text { Coefficients }\end{array}$ & t hitung & Sig. uji t \\
\hline & B & Std. Error & Beta & & \\
\hline (Constant) & $-0,514$ & 0,680 & & $-0,756$ & 0,451 \\
\hline Brand & 0,346 & 0,074 & 0,308 & 4,695 & 0,000 \\
\hline $\begin{array}{l}\text { Awareness }(\mathrm{X}) \\
\text { Word of Mouth } \\
\text { (Y) }\end{array}$ & 0,618 & 0,064 & 0,632 & 9,637 & 0,000 \\
\hline R Square & 0,766 & & & & \\
\hline F Statistik & 174,992 & & & & \\
\hline $\begin{array}{l}\text { Signifikansi Uji } \\
\text { F }\end{array}$ & 0,000 & & & & \\
\hline
\end{tabular}

Hasil Analisis Jalur 2

Berdasarkan hasil analisis jalur substruktur 2 seperti yang disajikan pada Tabel 7, maka dapat dibuat persamaan struktural sebagai berikut:

$$
\begin{gathered}
\mathrm{Y}=\beta 1 \mathrm{X}+\beta 3 \mathrm{M}+\mathrm{e} 2 \\
\mathrm{Y}=0,308 \mathrm{X}+0,632 \mathrm{M}+\mathrm{e} 2
\end{gathered}
$$

Nilai koefisien regresi masing-masing variabel bebas bernilai positif dengan nilai signifikansi uji t kurang dari 0,05 . Hal ini menunjukkan bahwa semua variabel bebas memiliki pengaruh positif dan signifikan terhadap variabel terikat. Besarnya pengaruh variabel bebas terhadap variabel terikat yang ditunjukkan oleh nilai determinasi total (R Square) sebesar 0,766 mempunyai arti bahwa sebesar 76,6\% variasi Purchase Intention dipengaruhi oleh variasi Brand Awareness dan Word of Mouth, sedangkan sisanya sebesar 23,4\% dijelaskan oleh faktor lain yang tidak dimasukkan ke dalam model.

Berdasarkan model substruktur 1 dan substruktur 2, maka dapat disusun model diagram jalur akhir. Sebelum menyusun model diagram jalur akhir, terlebih dahulu dihitung nilai standar eror sebagai berikut :

(1) $\mathrm{Pe}_{\mathrm{i}}=\sqrt{1-R i^{2}}$

(2) $\mathrm{Pe}_{1}=\sqrt{1-R 1^{2}}=\sqrt{1-0,491}=0,713$

(3) $\mathrm{Pe}_{2}=\sqrt{1-R 2^{2}}=\sqrt{1-0,766}=0,484$ 
Berdasarkan perhitungan pengaruh error $\left(\mathrm{Pe}_{\mathrm{i}}\right)$ didapatkan hasil pengaruh error $\left(\mathrm{Pe}_{1}\right)$ sebesar 0,713 dan pengaruh error $(\mathrm{Pe} 2)$ sebesar 0,484. Hasil koefisien determinasi total adalah sebagai berikut :

$$
\text { (1) } \begin{aligned}
\mathrm{R}_{\mathrm{m}}^{2} & =1-\left(\mathrm{Pe}_{1}\right)^{2}\left(\mathrm{Pe}_{2}\right)^{2} \ldots \ldots \\
& =1-(0,713)^{2}(0,484)^{2} \\
& =0,881
\end{aligned}
$$

Nilai determinasi total sebesar 0,881 mempunyai arti bahwa sebesar 88,1\% variasi Purchase Intention dipengaruhi oleh variasi Brand Awareness dan Word of Mouth, sedangkan sisanya sebesar $11,9 \%$ dijelaskan oleh faktor lain yang tidak dimasukkan ke dalam model.

Berdasarkan hasil analisis pengaruh Brand Awareness terhadap Purchase Intention diperoleh nilai signifikansi sebesar 0,000 dengan nilai koefisien beta 0,308. Nilai signifikansi $0,000<0,05$ mengindikasikan bahwa $\mathrm{H}_{0}$ ditolak dan $\mathrm{H}_{1}$ diterima. Hasil ini memiliki arti bahwa Brand Awareness berpengaruh positif dan signifikan terhadap Purchase Intention produk Maybelline di Kota Denpasar. berikut :

Perhitungan pengaruh antar variabel dirangkum dalam Tabel 7 sebagai

\section{Tabel 7.}

Pengaruh Langsung dan Pengaruh Tidak Langsung serta Pengaruh Total Brand Awareness (X), Word of Mouth (M), dan Purchase Intention (Y)

\begin{tabular}{lccc}
\hline $\begin{array}{c}\text { Pengaruh } \\
\text { Variabel }\end{array}$ & $\begin{array}{c}\text { Pengaruh } \\
\text { Langsung }\end{array}$ & $\begin{array}{c}\text { Pengaruh Tidak Langsung } \\
\text { melalui Word of Mouth (Y1) } \\
(\mathbf{\beta 1} \text { x } \beta 3)\end{array}$ & Pengaruh Total \\
\hline $\mathrm{X} \rightarrow \mathrm{M}$ & 0,700 & & 0,700 \\
$\mathrm{X} \rightarrow \mathrm{Y}$ & 0,308 & 0,442 & 0,750 \\
$\mathrm{M} \rightarrow \mathrm{Y}$ & 0,632 & & 0,632 \\
\hline
\end{tabular}

Sumber : Data diolah, 2018

Tabel 7. menunjukkan bahwa pengaruh langsung Brand Awareness (X) terhadap Word of Mouth (Y1) adalah sebesar 0,700. Pengaruh langsung variabel Brand Awareness (X) terhadap Purchase Intention (Y) adalah sebesar 0,308. Pengaruh langsung variabel Word of Mouth (M) terhadap Purchase Intention (Y) sebesar 0,632. Hal ini menandakan bahwa variabel Purchase Intention lebih besar dipengaruhi oleh Word of Mouth daripada Brand Awareness. Adapun pengaruh tidak langsung variabel Brand Awareness (X) terhadap Purchase Intention (Y) melalui Word of Mouth (Y1) adalah sebesar 0,750. Jadi dapat disimpulkan bahwa lebih besar total pengaruh Brand Awareness (X) terhadap Purchase Intention (Y) yang melalui Word of Mouth (M), daripada pengaruh langsung Brand Awareness terhadap Purchase Intention tanpa melalui Word of Mouth.

Untuk menguji signifikansi pengaruh tidak langsung maka nilai $\mathrm{z}$ dari koefisien ab dihitung dengan rumus sebagai berikut :

$$
\begin{aligned}
& \mathrm{Sab}=\sqrt{b^{2} S a^{2}+a^{2} S b^{2}+S a^{2} S b^{2}} \\
& \mathrm{Sab}=\sqrt{(0,681)^{2}(0,079)^{2}+(0,805)^{2}(0,064)^{2}+(0,079)^{2}(0,064)^{2}} \\
& \mathrm{Sab}=0,076
\end{aligned}
$$


Keterangan :

$\mathrm{Sab}=$ besarnya standar error tidak langsung

$\mathrm{Sa} \quad=$ standar error koefisien a

$\mathrm{Sb}=$ standar error koefisien $\mathrm{b}$

a $\quad=$ koefisien jalur $\mathrm{X}$ terhadap $\mathrm{M}$

$\mathrm{b} \quad=$ koefisien jalur $\mathrm{M}$ terhadap $\mathrm{Y}$

Untuk menguji signifikansi pengaruh tidak lansung, maka menghitung nilai $\mathrm{z}$ dari koefisien $\mathrm{ab}$ dengan rumus sebagai berikut :

$$
\begin{aligned}
Z & =\frac{a b}{S a b} \ldots \ldots \ldots . . \\
Z & =\frac{(0,805)(0,618)}{(0,076)} \\
Z & =6,51
\end{aligned}
$$

Oleh karena Z hitung sebesar 6,51 > 1,96 artinya Word of Mouth (M) merupakan variabel yang memediasi Brand Awareness terhadap Purchase Intention pada konsumen Maybelline kota Denpasar atau dengan kata lain Brand Awareness berpengaruh secara tidak langsung terhadap Purchase Intention melalui Word of Mouth.

Hasil pengujian mediasi dengan metode VAF dalam penelitian ini telah memenuhi beberapa persyaratan yaitu, pertama, pengaruh langsung ditemukan signifikan (a) saat variabel word of mouth (M) belum dimasukkan ke dalam model. Kedua, setelah variabel word of mouth (M) dimasukkan ke dalam model, maka pengaruh tidak langsung ( $\mathrm{b}$ x c) ditemukan pula signifikan. Jalur yaitu b dan c juga signifikan. Ketiga, menghitung Variance Accounted For (VAF) dengan rumus:

$$
\begin{aligned}
\mathrm{VAF} & =(0,700 \times 0,632) /(0,750+0,700 \times 0,632) \\
& =0,442 / 1,192 \\
& =0,371 \text { atau } 31,7 \text { persen. }
\end{aligned}
$$

Karena nilai VAF (37,1 persen) lebih dari 20 persen, maka dapat dijelaskan bahwa ada efek mediasi. Dengan demikian, maka hipotesis yang menyatakan bahwa word of mouth memediasi pengaruh Brand Awareness terhadap Purchase Intention konsumen diterima.

Hasil analisis menunjukkan bahwa Brand Awareness berpengaruh positif dan signifikan terhadap Purchase Intention. Hal ini memiliki makna bahwa semakin tinggi Brand Awareness yang dimiliki oleh konsumen terhadap Maybelline, maka semakin tinggi juga Purchase Intention yang dimiliki oleh konsumen terhadap Maybelline. Begitu juga sebaliknya, apabila Brand Awareness yang dimiliki Maybelline buruk maka semakin rendah juga Purchase Intention yang dimiliki konsumen Maybelline.

Hasil tersebut mengindikasikan bahwa nilai-nilai yang terkandung dalam Brand Awareness, mampu dipersepsikan dengan baik dan berdampak nyata pada Purchase Intention konsumen Maybelline di Kota Denpasar. Brand Awareness yang diukur berdasarkan indikator brand unaware, brand recognition, dan brand 
recall terbukti mampu meningkatkan Purchase Intention konsumen Maybelline di Kota Denpasar, yang mana hal ini dapat diartikan bahwa apabila Brand Awareness yang dimiliki Maybelline semakin tinggi, maka akan mampu memberikan kontribusi yang signifikan untuk meningkatkan Purchase Intention konsumen Maybelline di Kota Denpasar.

Penelitian ini juga mendukung beberapa hasil penelitian terdahulu yang dilakukan oleh Saputro dkk. (2016), Petahiang dkk. (2015), dan Chi et al. (2009) yang menyatakan bahwa Brand Awareness memiliki pengaruh yang positif dan signifikan terhadap Purchase Intention.

Hasil analisis menunjukkan bahwa Brand Awareness berpengaruh positif dan signifikan terhadap Word of Mouth. Hal ini memiliki makna bahwa semakin tinggi Brand Awareness yang dimiliki oleh konsumen terhadap Maybelline, maka semakin baik juga word of mouth yang disebarkan oleh konsumen Maybelline. Begitu juga sebaliknya, apabila Brand Awareness yang dimiliki Maybelline buruk maka semakin buruk juga word of mouth yang disebarkan oleh konsumen Maybelline.

Hasil tersebut mengindikasikan bahwa nilai-nilai yang terkandung dalam Brand Awareness, mampu dipersepsikan dengan baik dan berdampak nyata pada Word of Mouth Maybelline di Kota Denpasar. Brand Awareness yang diukur berdasarkan indikator brand unaware, brand recognition, dan brand recall terbukti mampu meningkatkan Word of Mouth Maybelline di Kota Denpasar, yang mana hal ini dapat diartikan bahwa apabila Brand Awareness yang dimiliki Maybelline semakin tinggi, maka akan mampu memberikan kontribusi yang signifikan untuk meningkatkan Word of Mouth Maybelline di Kota Denpasar.

Penelitian ini juga mendukung beberapa hasil penelitian terdahulu yang dilakukan oleh Katja et al. (2013), Barreda et al. (2015), Liao (2012) yang menyatakan bahwa Brand Awareness memiliki pengaruh yang positif dan signifikan terhadap Word of Mouth.

Hasil analisis menunjukkan bahwa Word of Mouth berpengaruh positif dan signifikan terhadap Purchase Intention. Hal ini memiliki makna bahwa semakin baik Word of Mouth yang diterima konsumen Maybelline, maka semakin tinggi juga Purchase Intention yang dimiliki oleh konsumen terhadap Maybelline. Begitu juga sebaliknya, apabila Word of Mouth yang diterima konsumen Maybelline buruk, maka semakin rendah juga Purchase Intention yang dimiliki konsumen Maybelline.

Hasil tersebut mengindikasikan bahwa nilai-nilai yang terkandung dalam Word of Mouth, mampu dipersepsikan dengan baik dan berdampak nyata pada Purchase Intention konsumen Maybelline di Kota Denpasar. Word of Mouth yang diukur berdasarkan mendapatkan informasi, menumbuhkan motivasi, dan mendapatkan rekomendasi dari orang lain terbukti mampu meningkatkan Word of Mouth Maybelline di Kota Denpasar, yang mana hal ini dapat diartikan bahwa apabila Word of Mouth mengenai Maybelline semakin baik, maka akan mampu memberikan kontribusi yang signifikan untuk meningkatkan Purchase Intention konsumen terhadap produk Maybelline di Kota Denpasar.

Penelitian ini juga mendukung beberapa hasil penelitian terdahulu yang dilakukan Andriyanto dan Haryanto (2010) yang menyatakan bahwa Word of 
Mouth memiliki pengaruh yang positif dan signifikan terhadap Purchase Intention.

Berdasarkan hasil Uji Sobel, ditemukan pengaruh yang positif antara variabel Brand Awareness terhadap Purchase Intention melalui variabel Word of Mouth dengan nilai $\mathrm{z}=6,51>1,96$ sehingga hipotesis keempat dalam penelitian ini diterima. Hal ini berarti bahwa Brand Awareness yang dimiliki Maybelline dan didukung oleh Word of Mouth yang baik terhadap Maybelline, secara tidak langsung dapat mempengaruhi Purchase Intention konsumen terhadap Maybelline. Brand Awareness yang dimiliki Maybelline dalam mempengaruhi Purchase Intention konsumen, harus memperhatikan dan mengutamakan word of mouth yang diterima oleh konsumen Maybelline tersebut. Dengan memiliki Brand Awareness yang baik, berpotensi mempengaruhi kesadaran konsumen tentang merek Maybelline yang pada akhirnya akan mempengaruhi Word of Mouth. Tingkat Word of Mouth Maybelline yang baik akan menyebabkan konsumen memiliki hasrat yang semakin tinggi untuk melakukan pembelian.

Penelitian yang dilakukan oleh Katja et al. (2013) menyatakan bahwa brand awareness berpengaruh positif dan signifikan terhadap WOM, yang berarti semakin tinggi brand awareness maka WOM akan semakin baik. Lin et al. (2013), menemukan bahwa word of mouth mempengaruhi Purchase Intention. Hal tersebut berarti semakin positif word of mouth yang diterima calon konsumen akan mampu meningkatkan Purchase Intention calon konsumen tersebut.

Hasil penelitian ini memberikan sebuah implikasi teoritis mengenai bagaimana pentingnya Brand Awareness dan Word of Mouth dapat mempengaruhi Purchase Intention. Hasil yang diperoleh dari penelitian ini menunjukkan hubungan secara langsung antar variabel, seperti hubungan antar variabel Brand Awareness dengan variabel Word of Mouth. Dalam penelitian ini menunjukkan bahwa apabila Brand Awareness yang dimiliki Maybelline semakin tinggi, maka akan mampu memberikan kontribusi yang signifikan untuk meningkatkan Word of Mouth Maybelline. Disamping itu terdapat hubungan secara langsung antara variabel Word of Mouth dengan Purchase Intention yang juga menandakan bahwa semakin tinggi word of mouth yang diterima konsumen Maybelline, maka semakin tinggi juga Purchase Intention yang dimiliki oleh calon konsumen Maybelline. Selain itu terdapat pula hubungan secara langsung antara variabel Brand Awareness dengan Purchase Intention yang memiliki makna bahwa semakin baik Brand Awareness terhadap Maybelline, maka semakin meningkat pula Purchase Intention yang dimiliki oleh konsumen Maybelline. Selain hubungan secara langsung, terdapat hubungan secara tidak langsung yang terjadi antara Brand Awareness terhadap Purchase Intention melalui Word of Mouth. Dengan tingginya Brand Awareness yang dimiliki Maybelline, berpotensi mempengaruhi persepsi calon konsumen terhadap Maybelline yang pada akhirnya akan mempengaruhi Word of Mouth yang mereka terima. Dengan adanya Word of Mouth Maybelline yang baik akan menyebabkan calon konsumen memiliki hasrat yang semakin tinggi untuk melakukan pembelian terhadap produk Maybelline. Implikasi penelitian ini dapat menggambarkan bahwa antara variabel Brand Awareness, Word of Mouth, dan Purchase Intention saling berkaitan. 
Upaya meningkatkan Brand Awareness menjadi lebih baik, dengan cara meningkatkan ingatan calon konsumen terhadap merek kosmetik Maybelline, dimana salah satunya melalui pihak manajemen Maybelline dapat melakukan iklan yang lebih sering sehingga brand Maybelline akan semakin melekat dalam ingatan konsumen sehingga membuat konsumen semakin ingat dengan merek Maybelline.

Upaya meningkatkan word of mouth menjadi lebih baik, dengan cara membuat teman-teman dari calon konsumen merekomendasi untuk membeli produk Maybelline, dimana salah satunya manajemen Maybelline membuat suatu bentuk promosi seperti melakukan pemberian kupon kepada konsumen Maybelline jika merekomendasikan untuk membeli produk Maybelline pada teman-temannya.

Upaya meningkatkan Purchase Intention menjadi lebih tinggi, dengan cara membuat calon konsumen lebih memilih produk Maybelline dibandingkan produk lainnya. Salah satu yang dapat dilakukan oleh pihak manajemen adalah dengan Maybelline dapat melakukan penguatan image-nya agar dimata konsumen Maybelline merupakan produk yang berkualitas. Hal ini dapat dilakukan dengan cara bekerjasama dengan influencer yang berkompeten atau berintegritas sehingga persepsi konsumen terhadap Maybelline itu semakin baik.

Ruang lingkup penelitian masih terbatas pada wilayah kota Denpasar dengan jumlah sampel sebanyak 110 orang, sehingga hasil penelitian ini tidak dapat digeneralisasi dalam lingkup yang lebih luas.

Penelitian ini hanya meneliti pengaruh variabel Brand Awareness terhadap Purchase Intention yang dimediasi oleh variabel Word of Mouth, sedangkan masih terdapat banyak faktor yang mempengaruhi Purchase Intention misalnya brand image, celebrity endorse, promotion, gaya hidup, dan masih banyak lagi sehingga penelitian ini penting untuk dilakukan kembali.

Penelitian ini hanya dilakukan dalam jangka waktu tertentu (cross section), sedangkan lingkungan dapat berubah setiap saat (dinamis), sehingga penelitian ini perlu dilakukan kembali dimasa mendatang.

\section{SIMPULAN}

Brand Awareness berpengaruh positif dan signfikan terhadap Purchase Intention calon konsumen Maybelline. Hal ini menunjukan bahwa semakin tinggi Brand Awareness konsumen maka Purchase Intention calon kosumen akan semakin tinggi terhadap produk Maybelline. Brand Awareness berpengaruh positif dan signfikan terhadap word of mouth yang diterima konsumen Maybelline. Hal ini menunjukan bahwa semakin tinggi Brand Awareness calon konsumen maka word of mouth yang diterima akan semakin baik oleh calon kosumen terhadap produk Maybelline.

Word of mouth berpengaruh positif dan signfikan terhadap Purchase Intention calon konsumen Maybelline. Hal ini menunjukan bahwa semakin baik word of mouth yang diterima calon konsumen maka Purchase Intention calon kosumen akan semakin tinggi terhadap produk Maybelline. Peran Word of Mouth memediasi secara signifikan hubungan Brand Awareness dengan Purchase Intention artinya Word of Mouth dinilai mampu memediasi hubungan Brand 
Awareness dengan Purchase Intention produk Maybelline lipstik matte dilihat dari hasil yang diperoleh dari teknik analisis yang berpengaruh positif dan signifikan.

Pada variabel Brand Awareness yang memiliki nilai terendah adalah Maybelline adalah merek produk kosmetik yang paling anda ingat oleh karena itu pihak Maybelline dapat meningkatkan periklanannya sehingga brand awareness Maybelline semakin meningkat dibenak konsumen. Pada variabel word of mouth yang paling rendah adalah teman-teman merekomendasikan anda untuk membeli Produk Maybelline, oleh karena itu pihak Maybelline melakukan promosi seperti melakukan pemberian kupon kepada konsumen Maybelline jika merekomendasikan untuk membeli produk Maybelline pada teman-temannya sehingga word of mouth Maybelline semakin baik. Pada variabel Purchase Intention yang memiliki nilai terendah adalah responden lebih memilih produk Maybelline dibandingkan produk lainnya, oleh karena itu Maybelline dapat melakukan penguatan image-nya agar dimata konsumen Maybelline merupakan produk yang berkualitas. Hal ini dapat dilakukan dengan cara bekerjasama dengan influencer yang berkompeten atau berintegritas sehingga persepsi konsumen terhadap Maybelline itu semakin baik dan dapat mendorong calon konsumen membeli produk Maybelline dibanding produk lainnya.

Untuk peneliti selanjutnya disarankan untuk mengambil wilayah berbeda dan dengan menggunakan variabel lainnya seperti brand image, celebrity endorse, promotion, gaya hidup, dan masih banyak lagi sehingga penelitian ini penting untuk dilakukan kembali.

\section{REFERENSI}

Aaker, David A. (2013). Manajemen Pemasaran Strategi. Edisi kedelapan. Salemba Empat. Jakarta.

Aditya, K. Y., \& Wardana, I. M. (2017). Peran Equity dalam Memediasi Pengaruh Word of Mouth terhadap Niat Beli. E-Jurnal Manajemen Universitas Udayana, 6(2), 830-856.

Andriyanto, R. D., \& Haryanto, J. O. (2010). Analisis Pengaruh Internet Marketing terhadap Pembentukan Word of Mouth dan Brand Awareness untuk Memunculkan Intention to Buy. Jurnal Manajemen Teknologi, 9(1), $20-35$.

Annafik, A. F., \& Rahardjo, M. (2012). Analisis pengaruh kualitas produk, harga, dan daya tarik iklan terhadap minat beli sepeda motor yamaha. Diponegoro Journal of Managemen, 1(2), 274-281.

Anwar, S., \& Gulzar, A. (2011). Impact of Perceived Value on Word of Mouth Endorsement and Customers Satisfaction: Mediating Role of Repurchase Intentions. International Journal of Economics, 1(5), 46-54.

Barreda, A. A., Bilgihan, A., Nusair, K., \& Okumus, F. (2015). Generating brand awareness in Online Social Networks. Computers in Human Behavior, 1-10. https://doi.org/10.1016/j.chb.2015.03.023

Basalamah, F. M. (2010). Pengaruh Komunitas Merek terhadap Word of Mouth. 
Jurnal Ilmu Administrasi Dan Organisasi, 17(1), 79-89.

Brown, J. J., \& Reingen, P. H. (1987). Social Ties and Word-of-Mouth Referral Behavior. Journal of Consumer Research, 14, 350-362.

Chi, H. K., Yeh, H. R., \& Yang, Y. T. (2009). The Impact of Brand Awareness on Consumer Purchase Intention: The Mediating Effect of Perceived Quality and Brand Loyalty. The Journal of International Management Studies, 4(1), 135-144.

Chiu, S., Liu, C., \& Tu, J. (2016). Journal of Air Transport Management The in fl uence of tourists 'expectations on purchase intention: Linking marketing strategy for low-cost airlines. Journal of Air Transport Management, 53(2), 226-234. https://doi.org/10.1016/j.jairtraman.2016.03.010

Hsu, Y., \& Hsu, Y. (2014). The Influence of Brand Awareness and Experiental Quality: Taking Manufacturer Brand and Private Labels as Examples. International Journal of Business and Commerce, 4(6), 84-98.

Katja, H., Hautz, J., Dennhardt, S., \& Fuller, J. (2013). The impact of user interactions in social media on brand awareness and purchase intention: the case of MINI on Facebook. Journal of Product \& Brand Management, 22(5), 342-351. https://doi.org/10.1108/JPBM-05-2013-0299

Kusuma, B. H. (2014). Analisis Pengaruh Promosi, Word of Mouth, dan Brand Awareness terhadap Pembentukan Minat Beli. Diponegoro Journal O, 4(1), 2337-3792.

Li, M.-H. (2010). The Influence of Perceived Service Quality on Brand Image, Word of Mouth, and Repurchase Intention: A Case Study of Min-Sheng General Hospital in Taoyuan, Taiwan Meng-Hsuan Li 1. Assumption University. International Journal of Business, 4(1), 91-105.

Liao, S. (2012). Relationships between brand awareness and online word-ofmouth: an example of online gaming community Chih-Chuang Wu Retno Widowati Mei-Ying Chen. International Journal Web Based Communities, $8(2), 177-195$.

Lin, C., Wu, Y. S., \& Chen, J. C. V. (2013). Electronic Word of Mouth: The Moderating Roles of Product Involvement and Brand Image. Technology Innovation and Industrial Management, 29-47.

Martinez, B., \& Kim, S. (2012). Predicting purchase intention for private sale sites. Journal of Fashion Marketing and Management, 4(1), 342-365. https://doi.org/10.1108/13612021211246080

Murtiasih, S., Sucherly, \& Siringoringo, H. (2013). How Word of Mouth Influence Brand Equity for Automotive Products in Indonesia. Procedia Social and Behavioral Sciences, 5(1), 40-44. https://doi.org/10.1016/j.sbspro.2013.06.384

Nurvidiana, R., Hidayat, K., \& Abdillah, Y. (2015). Pengaruh Word of Mouth terhadap Minat Beli Serta Dampaknya pada Keputusan Pembelian (Survei Pada Konsumen Republica Cafe Malang Jalan Mt. Haryono GgXI Malang). Jurnal Administrasi Bisnis (JAB), 22(2), 1-8.

Petahiang, I. L., Mekel, P., \& Worang, F. G. (2015). The Influence of Brand Awaresess and Perceived Risk Toward Consumer Purchase Intention on Online Store (Case Study of The Customer at FEB Unsrat Manado). Jurnal 
Berkala Ilmiah Efisiensi, 15(04), 481-492.

Ruhamak, M. D., \& Rahayu, B. (2016). Pengaruh Word of Mouth terhadap Puerchase Intention Melalui Brand Image pada Lembaga Kursus Bahasa Inggris Dynamic English Course Pare, 1(2), 188-204.

Saputro, R. Y., Paramita, P. D., \& Warso, M. M. (2016). Pengaruh brand awareness, perceved quality, dan price terhadap keputusan pembelian honda vario 125 di dealer astra honda semarang. Journal of Management, 2(2), 117.

Sudjianto, Z. P. (2014). Pengaruh Citra Merek, Kepercayaan Merek dan Kesadaran Merek terhadap Niat Beli Mahasiswa pada Sepatu Converse di Surabaya. E-Jurnal AGRO, 5(30), 1-9.

Sulistyowati, L. N. (2008). Pengaruh Persepsi Atas Produk dan Pelayanan Terhadap Kepuasan Pelanggan dan Perilaku Word Of MouthPada LBB "X" Maospati, Magetan. Media Soerjo, 3(2), 17-32.

Trisnawati, E., Suroso, A., \& Kumorohadi, U. (2012). Analisis faktor-faktor kunci dari niat pembelian kembali secara online (Study Kasus pada Konsumen Fesh Shop). Jurnal Bisnis Dan Ekonomi (JBE), 19(2), 126-141.

Widjaja, A. T. (2016). Pengaruh Word of Mouth dan Electronic Word of Mouth terhadap Purchase Intention: Sebuah Studi Kasus Mengenai Perilaku Konsumen terhadap Jasa Ojek Online Gojek. Jurnal Ekonomi Dan Bisnis, 53(12), 241-253.

Yaseen, N., Tahira, M., Gulzar, A., \& Anwar, A. (2011). Impact of Brand Awareness , Perceived Quality and Customer Loyalty on Brand Profitability and Purchase Intention: A Resellers ' View. Interdiciplinary Journal of Contemporary Research Business, 3(8), 833-839.

Zamil, A. M. (2011). The Impact of Word of Mouth ( WOM ) on the Purchasing Decision of the Jordanian Consumer. Research Journal of International Studies, 20(20), 24-29. 